\title{
Effects of Hypocapnia on Respiratory Timing and Inspiratory Activities of the Superior Laryngeal, Hypoglossal, and Phrenic Nerves in the Vagotomized Rat
}

\author{
Yasuichiro FUKUDA and Yoshiyuki HondA \\ Department of Physiology II, School of Medicine, \\ Chiba University, Chiba, Chiba, 280 Japan
}

\begin{abstract}
Effects of acute hypocapnia on respiratory timing (inspiratory and expiratory times $\left(T_{\mathrm{I}}, T_{\mathrm{E}}\right)$ ) and on inspiratory activities of the efferent superior laryngeal (Xsl), hypoglossal (XII), and phrenic (Phr) nerves were studied in artificially ventilated vagotomized, and anesthetized rats. Hyperventilation induced a decrease in respiratory frequency exclusively due to prolongation of $T E$ and resulted in expiratory apnea. Inspiratory activities of three nerves decreased with reduction in $\mathrm{CO}_{2}$ concentration of end-tidal gas $\left(\mathrm{FET}_{\mathrm{CO}_{2}}\right)$, and disappeared simultaneously at a threshold $F_{\mathrm{ET}_{\mathrm{CO}}}$ for apnea. The decrease in the peak inspiratory activity by hypocapnia was larger in the XII than in the $\mathrm{Phr}$ or $\mathrm{Xsl}$ nerve (XII $>\mathrm{Phr}>\mathrm{Xsl})$. The results suggest that the $\mathrm{CO}_{2}$ stimulus (mainly via a central chemosensor) plays an important role in the process of terminating expiration or of expiratory-inspiratory phase switching and that the responses of the XII or Xsl motoneurons to variation in $\mathrm{CO}_{2}$ stimulus differ from that of the $\mathrm{Phr}$ motoneurons (or of the Phr driving medullary neurons). A possible functional significance of these observations is discussed.
\end{abstract}

Key Words: rat, hypocapnia, respiratory timing, superior laryngealhypoglossal-phrenic respiratory activities.

Among many respiratory stimuli, carbon dioxide is the most important factor for regulating respiratory rhythm and for controlling neural signals to the respiratory muscles. We have previously demonstrated that the increase in the inspiratory neural activity by high $\mathrm{CO}_{2}$ is not similar among various efferent respiratory nerves (FuKUDA and HoNDA, 1982a, b). In the anesthetized rat with intact vagus nerves, inspiratory activities of the efferent vagal (superior laryngeal (Xsl)) and hypoglossal (XII) nerves innervating the upper airway respiratory muscles remained unchanged in hypercapnia which consistently increased the phrenic (Phr) discharge and respiratory frequency (FukUdA and Honda, 1982a). Follow-

Received for publication March 12, 1983

福田康一郎, 本田良行 
ing bilateral vagotomy, the XII and Xsl inspiratory discharges become augmented by high $\mathrm{CO}_{2}$, but there were extreme quantitative differences in the $\mathrm{CO}_{2}$-inspiratory activity responsiveness between the XII, Xsl, and Phr nerves (FukUDA and HoNDA, 1982b). Recently WEINER et al. (1982) found that hypercapnia induced different changes in the inspiratory activity between the XII, recurrent laryngeal and Phr nerves of the dog. These observations indicate that various groups of inspiratory output neurons in the bulbo-pontine respiratory complex may be differentially stimulated by excitatory signals from the central $\left(\mathrm{CO}_{2}^{-}\right)$chemosensor.

A decrease in the $\mathrm{CO}_{2}$ stimulus, on the other hand, reduces inspiratory neural activities and interrupts the generation of respiratory rhythm (hypocapnic apnea). In the present experiments on the artificially ventilated rat we recorded the inspiratory discharges of the Xsl, XII, and Phr nerves during passive hyperventilation until apnea ensued. The purpose of the study is firstly to observe effects of hypocapnia on the respiratory phase relation (inspiratory and expiratory times ( $T$ I and $T \mathrm{E})$ ) and secondly to confirm whether changes in the inspiratory activity due to reduced $\mathrm{CO}_{2}$ stimulus are also different among these three respiratory nerves.

\section{METHODS}

Eleven male albino rats (Wistar strain) weighing 250-450 g were anesthetized with halothane (induction 2.5\%, maintenance 0.9-1.1\%). The animal was placed on a stereotaxic frame in supine position and a tracheal cannula (polyethylene tubing) was inserted caudal to the larynx. The recurrent laryngeal nerves were separated and sectioned bilaterally before tracheostomy. The open end of the tracheal cannula was connected to a $\mathrm{T}$ - or $\mathrm{Y}$-shaped adaptor through which a halothane- $\mathrm{O}_{2}$ mixture was given via one axis from an anesthesia equipment (FukUdA et al., 1982). To avoid possible influences on respiratory timing via vagal pulmonary afferents of changing the rate or depth of artificial ventilation, experiments were done on the vagotomized rat. After bilateral vagotomy in the mid cervical region, 5-7 mm caudal to the nodose ganglion, the animal was immobilized by pancuronium bromide (Mioblock ${ }^{\circledR}$, Organon, $0.1 \mathrm{mg} / \mathrm{kg}$, i.v., every $1 \mathrm{hr}$ ) for artificial ventilation with a respirator (Narishige Scientific, Tokyo, Type AR-2). Respiratory gas was continuously sampled through a stainless steel tube (internal diameter, $0.5 \mathrm{~mm}$ ) placed in the trachea and the $\mathrm{CO}_{2}$ fraction of end-tidal gas $\left(\mathrm{FET}_{\mathrm{CO}_{2}}, \%\right)$ was monitored by an infrared absorption analyzer (San-Ei Instruments, Tokyo, 1H21) (Fukuda et al., 1982). The $F_{\mathrm{ET}_{\mathrm{CO}_{2}}}$ was initially controlled at a level of about $6.1 \%$ (range, 5.5-7.2\%), the value measured in the spontaneously breathing vagotomized anesthetized rat, by adjusting the rate of respirator at a constant stroke volume $(2.0-3.0 \mathrm{ml})$. All experiments were performed under hyperoxic conditions. Body temperature was kept constant at $37.7 \pm 0.2^{\circ} \mathrm{C}$ by using an electric heating pad and a precision temperature regulator 
with a thermistor probe placed in the rectum.

The Phr, Xsl, and XII (ascending branch) nerves were sectioned unilaterally, and the efferent respiratory neural activities were recorded from the central cut end of whole nerves by bipolar silver electrodes in warm mineral oil. Inspiratory discharges of the Xsl nerve initiate the contraction of the cricothyroid muscle (glottis dilator), and the XII nerve activity contributes to the forward protrusion of the tongue and to the dilation of pharyngeal space which are important in preserving upper airway patency during inspiration. Action potentials were amplified and fed into a band pass filter $(50-5,000 \mathrm{~Hz})$, a half wave rectifier and then a leaky integrator (time constant, $0.02 \mathrm{sec}$ ). $\quad \mathrm{FET}_{\mathrm{CO}_{2}}$ and integrated neural activities were registered on a pen recorder.

The $F \mathrm{ET}_{\mathrm{CO}_{2}}$ was reduced from a control value of $6.1 \pm 0.6 \%$ (mean \pm S.D.) to a level at which hypocapnic apnea occurred by increasing the rate of respirator at a constant stroke volume $(2.0-3.0 \mathrm{ml})$. Slow but sustained hypocapnia often induced intractable irregular and high frequency respiratory rhythm (hypocapnic polypnea) which, when occurring, could not be ceased even in extreme hypocapnia $\left(F \mathrm{ET}_{\mathrm{CO}_{2}} 2.0-3.0 \%\right.$ ). Therefore we reduced the $\mathrm{FET}_{\mathrm{CO}_{2}}$ from a control value to the apneic threshold level within 3-4 min, and changes in neural activities in three respiratory nerves $\left(\mathrm{CO}_{2}\right.$-"off" response) were analyzed.

\section{RESULTS}

\section{1) Changes in respiratory timing}

In the present experiments, inspiratory activities synchronized with the $\mathrm{Phr}$ discharge were always recorded from the XII and Xsl nerves. During passive hyperventilation, both the respiratory frequency $(f)$ and inspiratory activities of three nerves decreased progressively with decrease in the $\mathrm{FET}_{\mathrm{CO}_{2}}$ (Figs. 1 and 2). The reduction in $f$ was small until the $\mathrm{FET}_{\mathrm{CO}_{2}}$ reached a level of about $5 \%$, but $f$ fell off sharply with further decrease in $\mathrm{FET}_{\mathrm{CO}_{2}}$. Hypocapnic apnea appeared at the

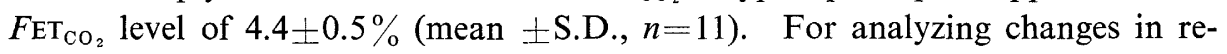
spiratory timing, $T \mathrm{I}$ and $T \mathrm{E}$ were measured from the $\mathrm{Phr}$ nerve recording (integrated activity). The $T_{I}$ was defined as the duration of time from the onset to the peak Phr inspiratory activity. Respiratory cycle duration $\left(T_{\text {Tot }}\right)$ was the time from the onset to the next onset of the Phr discharge, and $T_{\text {Tot }}-T_{\mathrm{I}}$ gave the $T \mathrm{E}$. As can be seen in Fig. 2 and Table 1, reduction in $f$ was mainly due to extreme prolongation of $T_{\mathrm{E}}$ with only slightly lengthened $T_{\mathrm{I}}$ resulting in expiratory apnea. The ratio of $T_{\mathrm{I}}$ to $T_{\text {Tot }}\left(T_{\mathrm{I}} / T_{\text {Tot }}\right.$, an index of "respiratory timing") was decreased by hypocapnia, which indicated disproportional changes in $T_{\mathrm{I}}$ and $T \mathrm{E}$. In previous papers (FUKUDA and HoNDA, 1982a, b) we noticed remarkable time lags in the onset of inspiratory activity between the Xsl, XII, and Phr nerves, i.e., the start of the Xsl and XII inspiratory activities preceded the onset of Phr discharges. When the $\mathrm{FET}_{\mathrm{CO}_{2}}$ was decreased, such temporal differences became less prominent 


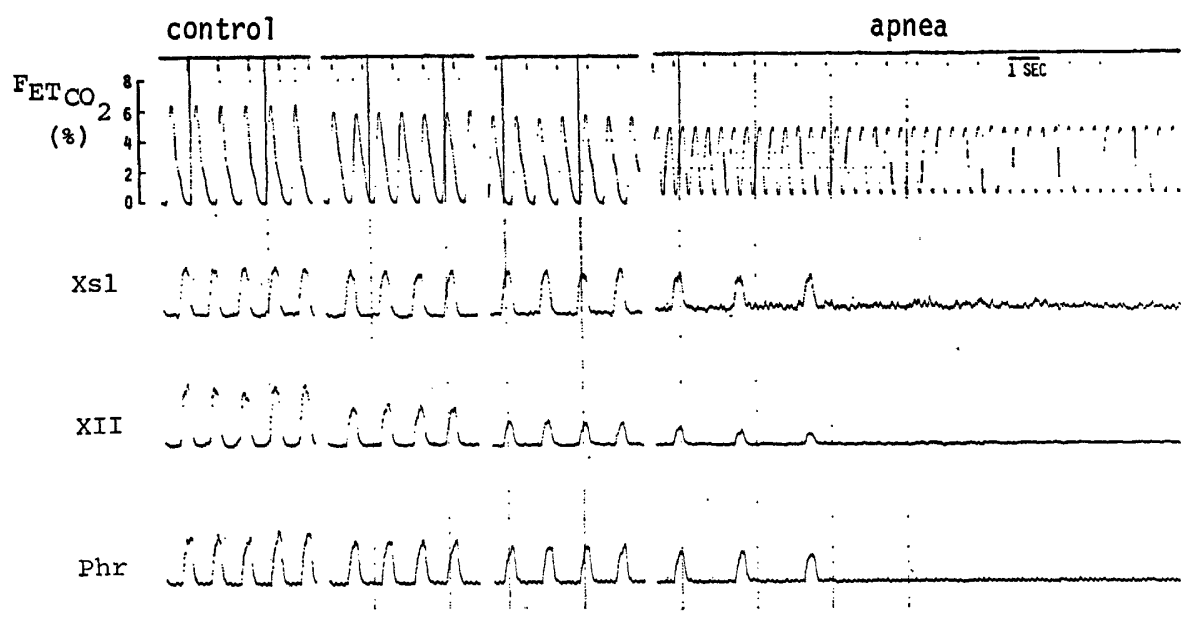

Fig. 1. Effect of hypocapnia on efferent respiratory neural activities of vagal (superior laryngeal), hypoglossal, and phrenic nerves in vagotomized, artificially ventilated and anesthetized rat. "Integrated" neural activities are shown. $F_{\mathrm{ET}} \mathrm{CO}_{2}, \mathrm{CO}_{2}$ fraction of end-tidal gas (\%); Xsl, vagal (superior laryngeal) nerve activity; XII, hypoglossal nerve activity; Phr, phrenic nerve activity.

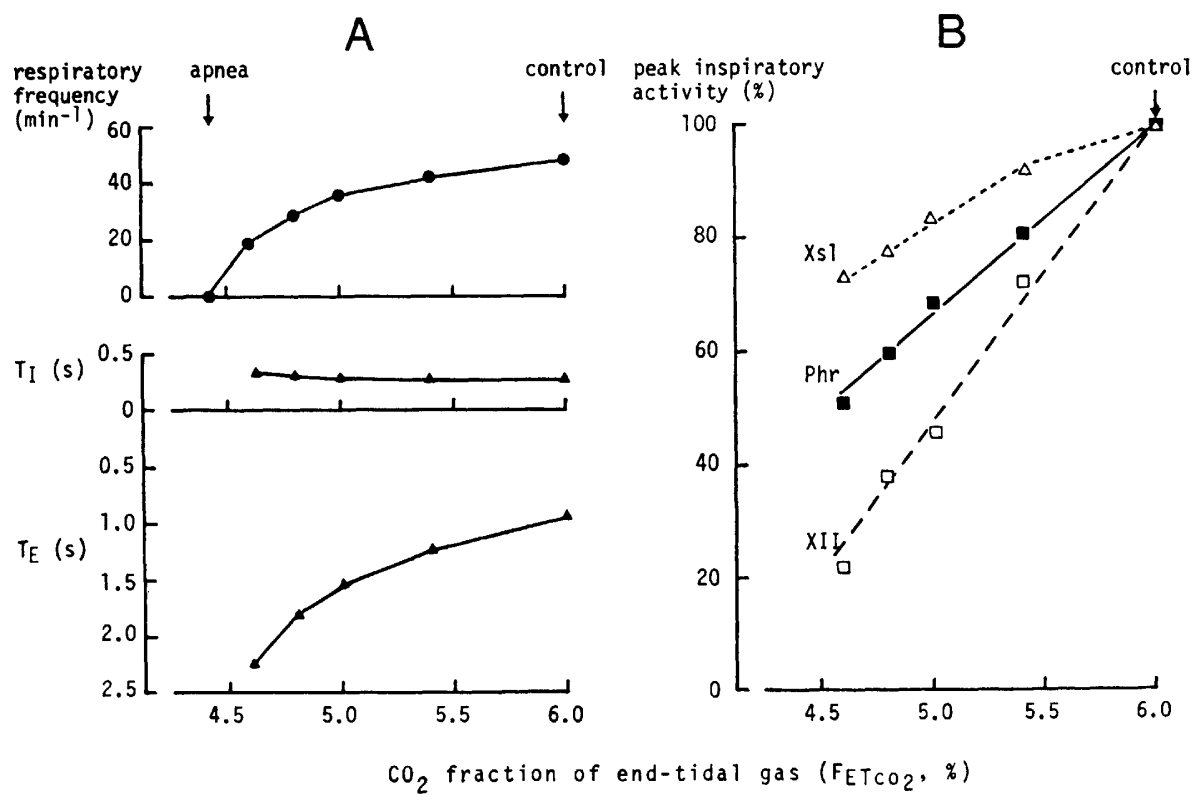

Fig. 2. Effect of hypocapnia on respiratory frequency, respiratory times and peak inspiratory activities. A, changes in respiratory frequency and respiratory times $\left(T_{\mathrm{I}}\right.$, inspiratory time; $T_{\mathrm{E}}$, expiratory time); B, changes in peak inspiratory activity (Xsl, vagal (superior laryngeal) nerve; XII, hypoglossal nerve; Phr, phrenic nerve). A and B were obtained from the same animal. 
Table 1. Effects of hypocapnia on respiratory frequency and respiratory times.

\begin{tabular}{|c|c|c|c|c|c|}
\hline $\begin{array}{c}F \mathrm{ET}_{\mathrm{CO}_{2}} \\
(\%)\end{array}$ & $\begin{array}{l}\text { Number of } \\
\text { observations }\end{array}$ & $f\left(\min ^{-1}\right)$ & $T_{\mathrm{I}}(\mathrm{sec})$ & $T_{\mathrm{E}}(\mathrm{sec})$ & $\begin{array}{l}\text { Average depend- } \\
\text { ency of } f \text { on } \\
F \mathrm{ET}_{\mathrm{CO}_{2}} \\
(\text { decrease in } f \\
\left(\min ^{-1}\right) / 1 \% \\
F_{\mathrm{ET}_{\mathrm{CO}}} \% \\
\text { reduction) }\end{array}$ \\
\hline $\begin{array}{l}6.1 \pm 0.6 \\
\text { (control) }\end{array}$ & 11 & $46 \pm 5$ & $0.34 \pm 0.03$ & $0.97 \pm 0.10$ & \\
\hline $5.3 \pm 0.5$ & 11 & $38 \pm 8^{*}$ & $0.37 \pm 0.04$ & $1.28 \pm 0.34 * *$ & $18 \pm 7$ \\
\hline $4.5 \pm 0.5$ & 11 & $18 \pm 5^{* * *}$ & $0.41 \pm 0.07^{*}$ & $* 3.11 \pm 0.83^{* * *}$ & \\
\hline
\end{tabular}

Values are mean \pm S.D. Asterisk(s), statistically significant difference between control value and value obtained in hypocapnia $(*, p<0.02 ; * *, p<0.01 ; * * *, p<0.001)$.

Table 2. Effect of hypocapnia on inspiratory activity.

\begin{tabular}{|c|c|c|c|c|}
\hline \multirow[t]{2}{*}{$F_{\mathrm{ET} \mathrm{CO}_{2}}(\%)$} & \multicolumn{3}{|c|}{ Peak inspiratory activity $(\%)$} & $\begin{array}{c}\text { Average dependency of peak } \\
\text { activity on } F_{\mathrm{ET}_{\mathrm{CO}_{2}}(\% \text { decrease }}(\% \mathrm{CET} \\
\text { in peak activity } / 1 \% \mathrm{FT}_{\mathrm{CO}_{2}} \\
\text { reduction) }\end{array}$ \\
\hline & Xsl & XII & $\mathrm{Phr}$ & XII \\
\hline $\begin{array}{l}6.1 \pm 0.6 \\
\text { (control) }\end{array}$ & 100 & 100 & 100 & \multirow{3}{*}{$18.4 \pm 8.737 .1 \pm 9.325 .1 \pm 7.9$} \\
\hline $5.3 \pm 0.5$ & $86.0 \pm 11.9^{* *}$ & $54.8 \pm 23.7^{*}$ & $73.1 \pm 11.0$ & \\
\hline $4.5 \pm 0.5$ & $67.5 \pm 14.5^{* * *}$ & $33.6 \pm 16.3^{* * *}$ & $56.0 \pm 9.5$ & \\
\hline $\begin{array}{r}\text { Valu } \\
\text { cantly di } \\
p<0.02 ; \\
{ }^{+}, p<0.0\end{array}$ & $\begin{array}{l}\text { es are mean } \pm S . I \\
\text { fferent from th } \\
* * *, p<0.001) \\
01 ; \text { N.S., not sig }\end{array}$ & $\begin{array}{l}\text { D. }(n=11) . \\
\text { at of the Phr } \mathrm{n} \\
\dagger^{\dagger \dagger} \text {, statistically } \\
\text { gnificant). }\end{array}$ & $\begin{array}{l}\text { es of the Xsl } \\
\text { rve at the sa } \\
\text { significant dif }\end{array}$ & $\begin{array}{l}\mathrm{d} \text { XII peak activity were signifi- } \\
\mathrm{FET}_{\mathrm{CO}_{2}} \text { level }\left(^{*}, p<0.05 ; * *\right. \\
\text { ence between pairs }\left(^{\dagger}, p<0.01\right.\end{array}$ \\
\hline
\end{tabular}

and they were difficult to determine accurately in a lower range of $\mathrm{FET}_{\mathrm{CO}_{2}}$ close to the threshold for apnea.

\section{2) Changes in inspiratory activities}

The peak inspiratory activity of three nerves decreased linearly with reduction in the $\mathrm{FET}_{\mathrm{CO}_{2}}$ (Fig. 2). In the case of the Xsl nerve, however, the peak activity decreased significantly at $\mathrm{FET}_{\mathrm{CO}_{2}}$ levels lower than $5.5 \%$. Among three nerves, the XII nerve showed the largest reduction in the peak activity and the Xsl nerve the least (Table 2). At average $\mathrm{FET}_{\mathrm{CO}_{2}}$ of $4.5 \pm 0.5 \%$ which was slightly higher than the threshold for apnea, $68 \%$ of the control activity remained in the Xsl nerve whereas the XII and Phr nerve activities decreased to 34 and $56 \%$ of respective control values. Although the peak activity decreased differentially in the XII, Xsl, and Phr nerves, none of three nerves ceased inspiratory firing earlier than the other before $F \mathrm{ET}_{\mathrm{CO}_{2}}$ reached the threshold for apnea (simultaneous disappearance). In Table $2 \mathrm{CO}_{2}$-inspiratory activity responsiveness of three nerves 
was expressed as percentage change per $1 \%$ reduction in $\mathrm{FET}_{\mathrm{CO}_{2}}$. The XII nerve exhibited the largest $\mathrm{CO}_{2}$-"sensitivity" and the average dependency to $\mathrm{CO}_{2}$ of the Xsl nerve was less than that of the $\mathrm{Phr}$ nerve. The result indicated that inspiratory activity responses to diminished $\mathrm{FET}_{\mathrm{CO}_{2}}$ differ quantitatively in various respiratory nerves. This was completely compatible with the previous observation on the spontaneously breathing vagotomized rat that the sensitivity of $\mathrm{CO}_{2}$-inspiratory activity response was in the following order; the XII larger than the Phr or Xsl (XII $>$ Phr $>$ Xsl) (FuKudA and Honda, 1982b).

\section{DISCUSSION}

General. We investigated the respiratory phase relation and inspiratory discharges of three respiratory nerves while reducing the $\mathrm{CO}_{2}$ stimulus which seemed to influence the bulbo-pontine respiratory complex mainly via the central $\left(\mathrm{CO}_{2}-\right)$ chemosensor. Ablation by coagulation or local cooling of the ventral medullary chemosensitive area abolishes completely the ventilatory or Phr activity responses to $\mathrm{CO}_{2}$ (CHERNIACK et al., 1979; SCHLAEFKE et al., 1979). Inspiratory discharges of various efferent nerve fibers are expected to reflect the overall state of firing in the different groups of inspiratory output neurons, i.e., the XII or XsI motoneurons in the medulla oblongata and the spinal cord $\mathrm{Phr}$ motoneurons (or the Phr driving medullary neurons) which are commonly governed by a primary respiratory rhythm generator. Since relatively well preserved activity of three respiratory nerves disappeared simultaneously at the threshold $\mathrm{FET}_{\mathrm{CO}_{2}}$ for apnea, a rapid reduction in $\mathrm{CO}_{2}$ stimulus might be more critical for generating respiratory rhythm than for maintaining the excitability of inspiratory output neurons. In general, hypocapnia increases the excitability of the central nervous neurons, e.g., Phr motoneuron (GILL and KUNO, 1963).

Respiratory timing. The decrease in $\mathrm{FET}_{\mathrm{CO}_{2}}$ initiated marked prolongation of $T \mathrm{E}$ and the expiratory apnea. Although some investigators found that changes in the $\mathrm{CO}_{2}$ stimulus caused little or no change in $T \mathrm{E}$ in the vagotomized animals (Miserocchi and Milic-Emili, 1975; Shannon, 1976; Widdicombe and WinNing, 1974), the present result supports previous observations that the change in $f$ by $\mathrm{CO}_{2}$ stimulus in vagi denervated as well as intact animals is exclusively due to alteration in TE (GAUTIER et al., 1973; LedLIE et al., 1981). The explanation for these different changes in $T E$ of various studies is not apparent because data were obtained in different species of animals and under various anesthetic conditions. EYZAGUIRRE and TAYLOR (1963) showed that inspiratory fibers in the Phr and recurrent laryngeal nerves lost their activity in low $\mathrm{CO}_{2}$. The expiratory activity of the latter nerve fibers, on the other hand, increased in response to low $\mathrm{CO}_{2}$ and became tonically active when hypocapnic apnea was induced. A similar response to low $\mathrm{CO}_{2}$ was recorded from the brain stem respiratory neurons (BASTEL, 1967; COHEN, 1968; FALlert et al., 1977). These observations indicate that hypocapnia 
causes expiratory apnea. Accordingly the reduction in $\mathrm{CO}_{2}$ stimulus (via central chemosensor) seems to play an important role in the process of termination of expiration or of expiratory-inspiratory phase switching. The process of inspiratory off-switching, on the other hand, was thought to be little affected by hypocapnia because changes in $T_{I}$ were small. When the function of the central chemosensor was blocked by applying local anesthetic (procaine) on the ventral medullary surface layer, expiratory neurons in the deeper medulla either fired continuously or decreased firing whereas inspiratory neurons were greatly inhibited or ceased firing (SCHWANGHART et al., 1974), which shows that the loss of central chemosensor activity may produce expiratory apnea. However, nothing is known of actions of central chemosensor afferents on the neural mechanism responsible for termination of expiration.

Inspiratory activity. Hypocapnia decreased the inspiratory discharge of three respiratory nerves. The peak activity of the Xsl nerve was, however, relatively well preserved in low $\mathrm{FET}_{\mathrm{CO}_{2}}$. The XII nerve, on the other hand, showed the largest reduction in activity during hypocapnia. There are evidences showing that the $\mathrm{CO}_{2}$ stimulus induces a larger change in phasic XII nerve (or genioglossus muscle) inspiratory activities than that in the Phr (or diaphragmatic) discharges (BRouilletTe and THACH, 1980; WeINer et al., 1982). In the dog the phasic XII nerve activity disappeared more quickly than that of the Phr burst during hyperventilation (WEINER et al., 1982). These data suggest that the response of the XII motoneurons to $\mathrm{CO}_{2}$ stimulus is quantitatively different from that of the $\mathrm{Phr}$ motoneurons or of the $\mathrm{Phr}$ driving medullary neurons in that recruitment or rate of discharge of neurons differs between two neuron groups. The Xsl motoneurons seem to be less influenced by changes in $\mathrm{CO}_{2}$ stimulus than the XII or Phr motoneurons. Decrease in the number of activated neurons or in the rate of discharge of the Xsl motoneurons may be small in hypocapnia. Although Mitchell and HERBERT (1974) found that excitatory synaptic inputs to the medullary inspiratory neurons are increased with high $\mathrm{CO}_{2}$ and diminished with lowered $\mathrm{CO}_{2}$, little is known of the neural pathways between the central chemosensor and the XII or Xsl inspiratory output neurons. It is uncertain whether the excitatory signal from the central chemosensor is routed via the rhythm generator (MITCHELL and Berger, 1981; MitChell and Herbert, 1974) or if it affects respiratory neurons directly (BAINTON and KIRKWOOD, 1979).

Respiratory motor control in the upper airway (summary). The following discussion which is schematically illustrated in Fig. 3, summarizes the present series of experiments (present study and our previous observations (FUKUDA and HoNDA, 1982a, b)) in an attempt to understand the respiratory motor control in the upper airway. In the rat, alveolar ventilation which is predominantly controlled by $f$ (FUKUDA et al., 1982) depends on the presence of vagal afferents. Furthermore inspiratory activities of the XII and Xsl nerves and their increase in hypercapnia are more strongly inhibited by vagal afferents than those of the $\mathrm{Phr}$ 


\section{A. Vagi intact}

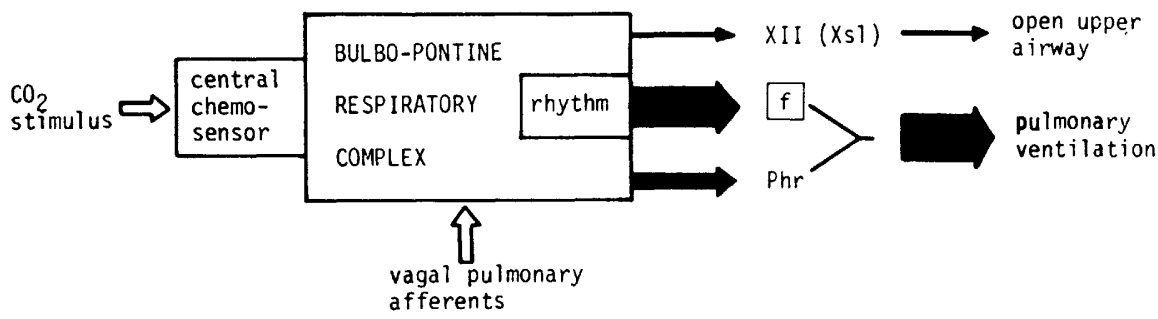

B. Vagi denervated

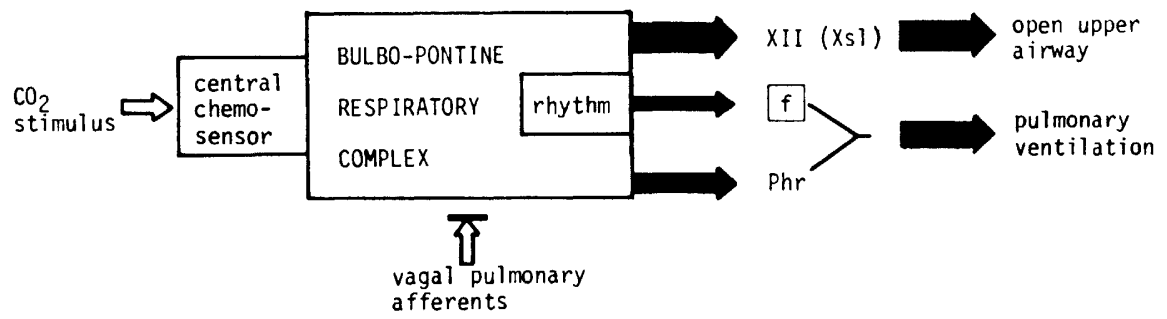

Fig. 3. Input-output relationship of respiratory control system in the rat (a simple model). Solid arrows indicate neural outputs (respiratory frequency $(f)$ and inspiratory activity) from the respiratory complex ("center"). Thickness of arrows represents relative magnitude of outputs. Open arrows indicate two major inputs $\left(\mathrm{CO}_{2}\right.$ stimulus and vagal pulmonary afferents) to the respiratory complex. rhythm, a respiratory rhythm generator; Xsl, vagal (superior laryngeal) efferent activity; XII, hypoglossal efferent activity; Phr, phrenic nerve activity. See text for explanation.

nerves (FUKUDA and HoNDA, 1982b). In the vagi intact rat, therefore, the bulbopontine respiratory complex regulates the output neural signals in such a way that the respiratory machinery operates to maintain adequate pulmonary ventilation via controlling $f$ and the Phr activity with minor activities for controlling respiratory muscles in the upper airway (Fig. 3A). A decrease in the alveolar ventilation due to strong reduction in $f$ and augmentation of the XII or Xsl inspiratory activity in normo- and hypercapnia ensue from bilateral vagotomy (FukUDA and Honda, 1982b). These changes in respiratory pattern are ascribed to the interruption of the pulmonary stretch receptor afferents responsible for HeringBreuer inflation reflex (WIDDICOMBE, 1964). A similar condition may occur even in the vagi intact animal when the upper airway is obstructed, for example by relapse of the tongue due to diminution of the genioglossus muscle activity (BRouillette and THACH, 1980; ReMmers et al., 1978). The airway obstruction prevents lung inflation and may inhibit the initiation of impulses in the pulmonary stretch receptors, the situation being analogous to the vagotomized state. Consequently increased inspiratory activities especially of the XII nerve, which are 
intensified by accumulation of $\mathrm{CO}_{2}$ during obstruction, protrude the tongue forward and open the pharyngeal space. Thus the central respiratory mechanism seems to initiate predominant motor activities in the upper airway muscles allowing adequate passage of air through the pharyngolaryngeal spaces (Fig. 3B). This may be an important physiological mechanism of releasing the upper airway closure.

The authors thank Professor Dr. T. Hukuhara, Jr. for valuable discussion in this series of experiments. This work was partly supported by a Research Grant from the Life Insurance Association of Japan.

\section{REFERENCES}

Bainton, C. R. and Kirkwood, P. A. (1979) The effect of carbon dioxide on the tonic and the rhythmic discharges of expiratory bulbospinal neurones. J. Physiol. (Lond.), 296: 291-314.

BASTEL, H. L. (1967) Activity of bulbar respiratory neurons during passive hyperventilation. Exp. Neurol., 19: 357-374.

Brouillette, R. T. and THACH, B. T. (1980) Control of genioglossus muscle inspiratory activity. J. Appl. Physiol., 49: 801-808.

Cherniack, N. S., von Euler, C., Honma, I., and KaO, F. F. (1979) Graded changes in central chemoreceptor input by local temperature changes on the ventral surface of the medulla. J. Physiol. (Lond.), 287: 191-211.

CoHEN, M. I. (1968) Discharge patterns of brain-stem respiratory neurons in relation to carbon dioxide tension. J. Neurophysiol., 31: 142-165.

EyzaGuirre, C. and TAYLOR, J. R. (1963) Respiratory discharge of some vagal motoneurons. J. Neurophysiol., 26: 61-78.

FALLeRT, M., BÖHMER, G., and DinSE, H. R. O. (1977) Patterns of bulbar respiratory neurons during and after artificial hyperventilation. Respir. Physiol., 29: 143-149.

FuKUdA, Y. and HoNDA, Y. (1982a) Differences in respiratory neural activities between vagal (superior laryngeal), hypoglossal and phrenic nerves in the anesthetized rat. Jpn. J. Physiol., 32: 387-398.

FuKUdA, Y. and Honda, Y. (1982b) Roles of vagal afferents on discharge patterns and $\mathrm{CO}_{2}$ responsiveness of efferent superior laryngeal, hypoglossal and phrenic respiratory activities in anesthetized rats. Jpn. J. Phyisol., 32: 689-698.

FukUda, Y., SEE, W. R., and Honda, Y. (1982) Effect of halothane anesthesia on end-tidal $P_{\mathrm{CO}_{2}}$ and pattern of respiration in the rat. Pflügers Arch., 392: 244-250.

Gautier, H., Remmers, J. E., and Bartlett, D., Jr. (1973) Control of the duration of expiration. Respir. Physiol., 18: 205-221.

Gill, P. K. and Kuno, M. (1963) Properties of phrenic motoneurones. J. Physiol. (Lond.), 168: $258-273$.

Ledue, J. F., Kelsen, S. G., Cherniack, N. S., and Fishman, A. P. (1981) Effects of hypercapnia and hypoxia on phrenic nerve activity and respiratory timing. J. Appl. Physiol., 51: $732-738$.

MiserocCHI, G. and MiLic-EMiLI, J. (1975) Contribution of hypercapnic stimuli and vagal afferents to the timing of breathing in anesthetized cats. Respir. Physiol., 25: 71-88.

Mitchell, R. A. and Berger, A. L. (1981) Neural regulation of respiration. In: Regulation of Breathing, Part I, ed. by HornbeIn, T. F. Marcel Dekker, Inc., New York-Basel, pp. 540620 .

Vol. 33, No. 5, 1983 
Mitchell, R. A. and Herbert, D. A. (1974) The effect of carbon dioxide on the membrane potential of medullary respiratory neurons. Brain Res., 75: 345-349.

Remmers, J. E., DeGroot, W. J., Sauerland, E. K., and ANCH, A. M. (1978) Pathogenesis of upper airway occlusion during sleep. J. Appl. Physiol., 44: 931-938.

Schlaefke, M. E., Kille, J. F., and LoeschCKe, H. H. (1979) Elimination of central chemosensitivity by coagulation of a bilateral area on the ventral medullary surface in awake cats. Pflügers Arch., 378: 231-241.

Schwanghart, F., Schroeter, R., Klüssendorf, D., and Koepchen, H. P. (1974) The influence of novocaine block of superficial brain stem structures on respiratory and reticular neurons. In: Central Rhythmic and Regulation, ed. by UMBACH, W. and Koepchen, H. P. Hippokrates, Stuttgart, pp. 104-110.

Shannon, R. (1976) Respiratory frequency control during hypercapnia in vagotomized, anesthetized cats. Respir. Physiol., 27: 357-367.

Weiner, D., Mitra, J., Salamone, J., and Cherniack, N. S. (1982) Effect of chemical stimuli on nerves supplying upper airway muscles. J. Appl. Physiol., 52: 530-536.

Widdicombe, J. G. (1964) Respiratory reflexes. In: Handbook of Physiology, Section 3, Respiration, Vol. I, ed. by FenN, W. O. and RaHN, H. American Physiological Society, Washington, D.C., pp. 585-630.

Widdicombe, J. G. and Winning, A. (1974) Effects of hypoxia, hypercapnia and changes in body temperature on the pattern of breathing in cats. Respir. Physiol., 21 : 203-221. 